\title{
A NEW LOW POWER MEMS DUAL MODE CLOCK WITH PPB STABILITY OVER TEMPERATURE
}

\author{
Lizmarie Comenencia Ortiz ${ }^{l}$, Hyun-Keun Kwon ${ }^{l}$, Janna Rodriguez ${ }^{1}$, David B. Heinz ${ }^{l}$, Yunhan Chen ${ }^{2}$, \\ Gabrielle D. Vukasin ${ }^{l}$, Dongsuk D. Shin ${ }^{l}$ and Thomas W. Kenny ${ }^{l}$ \\ ${ }^{1}$ Stanford University, California, USA \\ ${ }^{2}$ Apple Inc., California, USA
}

\section{ABSTRACT}

In this paper, we demonstrate a novel dual-mode clock with an in-chip device layer micro-oven which operates at $10 \mathrm{X}$ reduced power consumption and provides more than $30 \mathrm{X}$ improved stability when compared to a recent result with a micro-oven embedded in the cap [2]. The decrease in the thermal time constant and in the micro-oven power dissipation improves compensation for ambient temperature variations and allows for significant improvements in the stability. This device layer micro-oven enables correction for ambient temperature fluctuations and achieves long-term stability over temperature in $\mathrm{ppb}$, which is better than the stability of TCXOs and competes with state-of-the-art OCXOs, while requiring much less power.

\section{BACKGROUND AND DEVICE DESIGN}

A combination of passive and active temperature compensation methods can significantly improve the stability of encapsulated MEMS clocks [1-4]. Active compensation has been achieved previously with the use of a micro-oven embedded in the encapsulation lid of the die; while this method is successful in compensating for temperature changes $\left(+/-0.9 \mathrm{ppb} /{ }^{\circ} \mathrm{C}\right)$, it requires substantial power (approximately $3 \mathrm{~mW} /{ }^{\circ} \mathrm{C}$ ) [2]. The dissipated heat can affect the stability and performance of the device due to temperature gradients and thermal stresses. Previous work has shown that a micro-oven isolated within the device layer of the die can significantly reduce thermal stresses and the power required to ovenize $[4,9]$.

Here, we extend these efforts by combining the low-power of the device-layer planar suspension with the high-Q and highlinearity of a temperature-compensated Lamé-mode resonator. As shown in Figure 1A, micro-oven structures provide support and thermal isolation for a frame that contacts the dual-mode MEMS resonator at nodes of both vibrational modes.
(A)

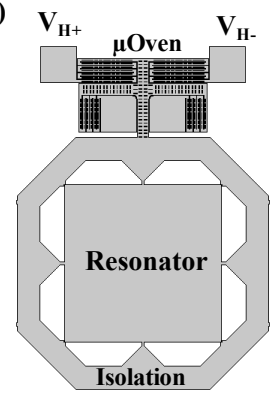

(B)

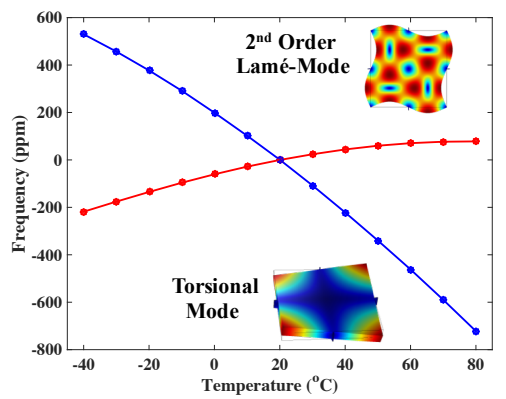

Figure 1: Schematic of dual mode clock: (A) dual Lamé-mode clock, (B) temperature dependence of frequency for each mode using closed loop frequency sweeps.

The devices are fabricated on p-type SOI wafer with a $40 \mu \mathrm{m}$ device layer using commercially-available, high-volume epitaxial thick film encapsulation processes. The temperature dependence of frequency for both modes was determined within a range of $-40^{\circ} \mathrm{C}$ to $80^{\circ} \mathrm{C}$, as shown in Figure $1 \mathrm{~B}$. Each mode was excited with a
Zurich Instruments digital lock-in amplifier and transimpedance amplifiers to amplify the resonators' signal as shown in Figure 2.

Table 1: Summarized clock properties and measurements.

\begin{tabular}{|c|c|c|}
\hline \multicolumn{2}{|c|}{ Properties } & Lamé-Mode Clock \\
\hline \multicolumn{2}{|c|}{ Doping } & P-type: $1 \mathrm{e} 20 \mathrm{~cm}^{-3}$ \\
\hline \multicolumn{2}{|c|}{ Geometry } & $400 \mu \mathrm{m} \times 400 \mu \mathrm{m}$ \\
\hline Mode 1 & $\begin{array}{l}\mathbf{f}_{1} \\
\mathbf{Q}_{1}\end{array}$ & $\begin{array}{c}20.16 \mathrm{MHz} \\
950 \mathrm{k}\end{array}$ \\
\hline Mode 2 & $\begin{array}{l}\mathbf{f}_{2} \\
\mathbf{Q}_{2}\end{array}$ & $\begin{array}{c}1.19 \mathrm{MHz} \\
770 \mathrm{k}\end{array}$ \\
\hline \multicolumn{2}{|c|}{$\mu$ Oven Power } & $0.18 \mathrm{~mW} /{ }^{\circ} \mathrm{C}$ \\
\hline \multicolumn{2}{|c|}{ Temperature Stability } & $<+/-1.5 p p b$ \\
\hline
\end{tabular}

By simultaneously exciting a pair of modes in the same structure, we can continuously determine temperature and provide a frequency reference using a control scheme that is common for quartz OCXOs [5]. The frequency for both modes was tracked with phase lock loops and the frequency difference was regulated by application of voltage across the micro-oven terminals using proportional and integral control.

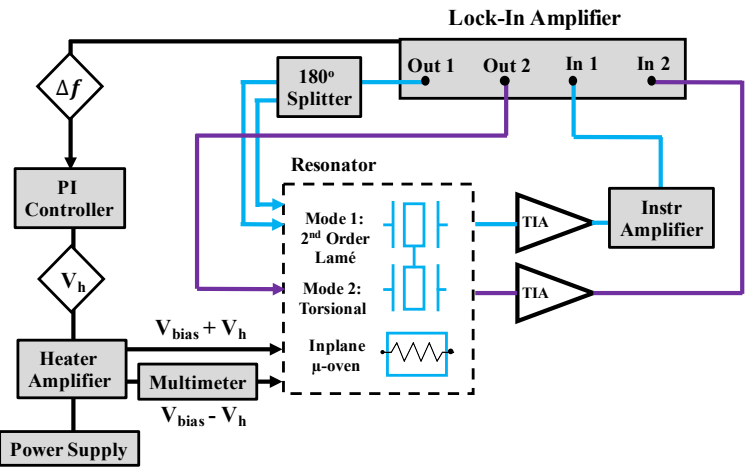

Figure 2: Schematic of experimental set up: a phase locked loop was used to simultaneously track the frequencies of two modes in one resonator. A PI controller was used to control the micro-oven voltage and maintain a constant turnover temperature of $80^{\circ} \mathrm{C}$.

\section{RESULTS}

This dual-Lamé-mode clock was operated at steady state at $-40^{\circ} \mathrm{C}$ over 12 hours, where $22 \mathrm{~mW}$ of micro-oven power is required to bring the resonating element to its turnover temperature of $80^{\circ} \mathrm{C}$. The Allan Deviation corresponding to this data indicates a minimum of $<0.2 \mathrm{ppb}$ at $1000 \mathrm{~s}$.

A stability of $+/-1.4 \mathrm{ppb}$ was achieved while ramping temperature from $-40^{\circ} \mathrm{C}$ to $60^{\circ} \mathrm{C}$ over 10 hours, as shown in Fig. 4 . These results exceed the best performance of all previouslypublished MEMS-based time references. Notably, this is the first MEMS device to demonstrate single-digit ppb stability over time and temperature. Figure 6 shows this new result in the context of prior products and academic demonstrations of MEMS-based and macroscopic time references. 


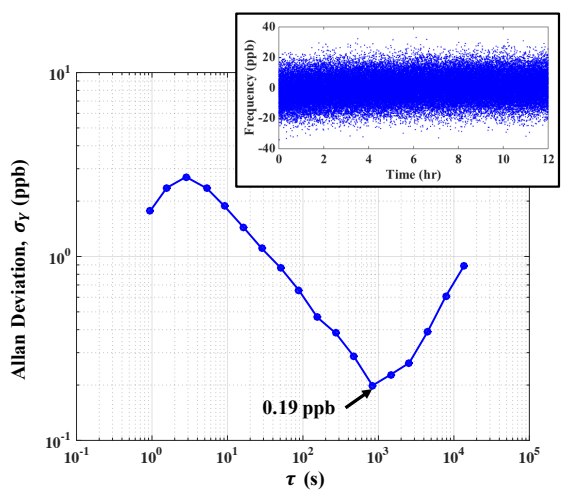

Figure 3: Allan deviation for $2^{\text {nd }}$ order Lamé-mode at an ambient temperature of $-40^{\circ} \mathrm{C}$ with $+/-0.3^{\circ} \mathrm{C}$ temperature fluctuations.
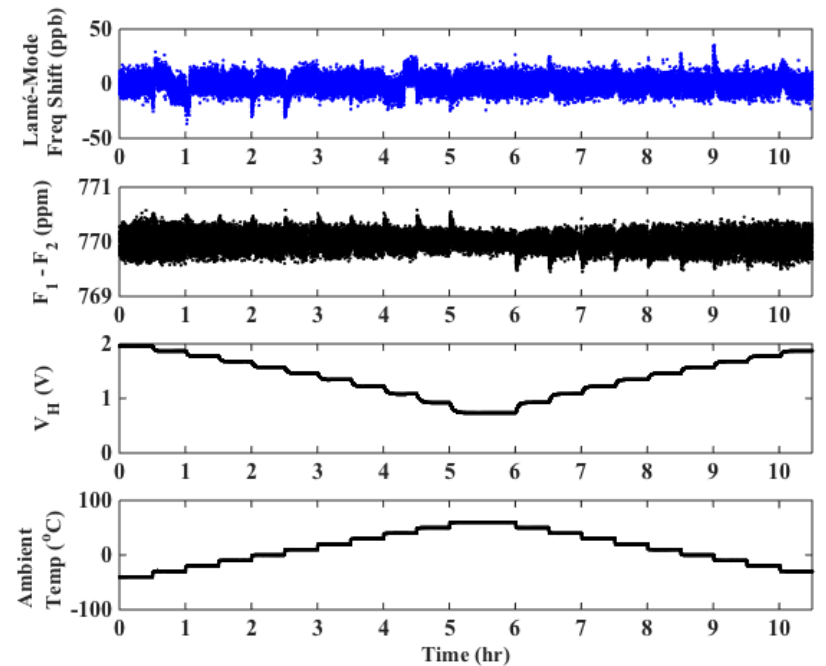

Figure 4: Frequency stability of $2^{\text {nd }}$ order Lamé-mode with changes in ambient temperature. Heater voltage is applied through the micro-oven to maintain the frequency at the turnover temperature.

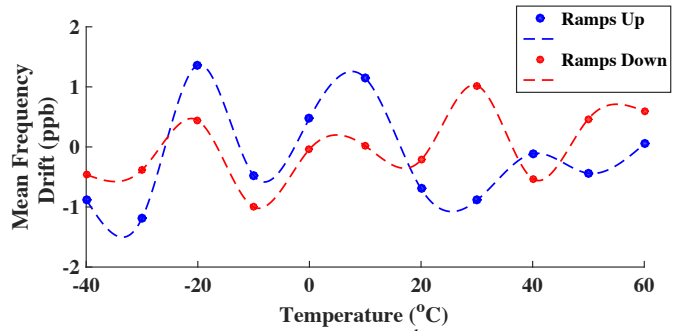

Figure 5: Mean frequency error of $2^{\text {nd }}$ order Lamé-mode at steady state with changes in ambient temperature.

\section{CONCLUSION}

In this paper, we demonstrate more than $30 \mathrm{X}$ improvement in the stability of a dual Lamé-mode clock and $10 \mathrm{X}$ reduction in the power consumption. We show that stiff Lamé-mode bulk resonators are ideal candidates for ultra-precise ovenized clocks since they are less susceptible to thermal expansion nonlinearities. Our results for temperature and long-term stability are the best of any previouslypublished or commercially produced MEMS-based clock, while also operating with heater power far below any conventional quartz OCXO.

These devices have the potential to revolutionize applications that require ultra-stable references and low power.

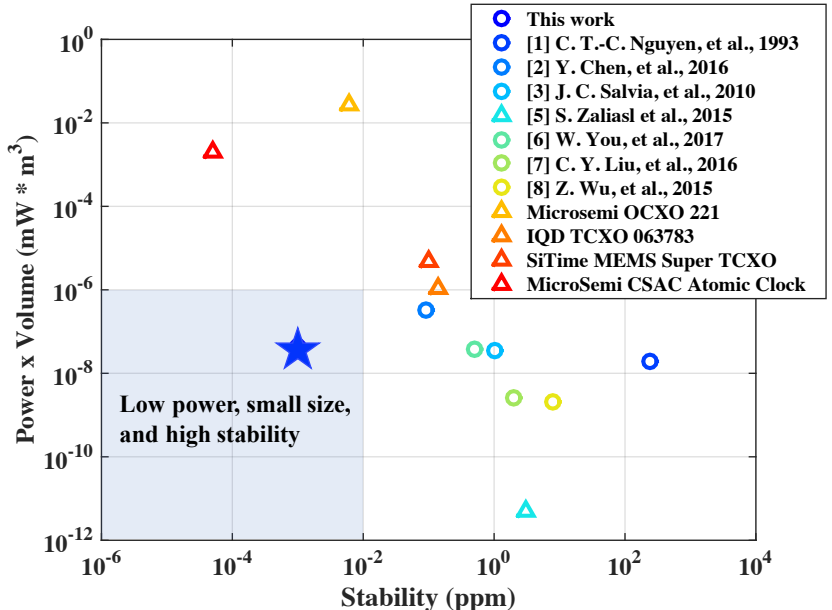

Figure 6: Comparison of clock stability over temperature $\left(-40^{\circ} \mathrm{C}\right.$ to $80^{\circ} \mathrm{C}$ ) for range of devices shows that the dual Lamé-mode clock (starred) has better stability and power consumption than leading TCXOs and OXCOs used in industrial applications.

[1] C. T.-C. Nguyen, and R. T. Howe, "Microresonator frequency control and stabilization using an integrated micro oven", in Technical Digest of the 1993 Transducers Conference, Yokohama, Japan, 6/7-10/93, IEEE, (1993), pp. 1040-1043.

[2] Y. Chen, E. J. Ng, D. D. Shin, C. H. Ahn, Y. Yang, I.B. Flader, V. A. Hong, and T. W. Kenny, "Ovenized Dual-Mode Clock (ODMC) Based on Highly Doped Single Crystal Silicon Resonators", Technical Digest of the 2016 MEMS Shanghai, China, 6/24-28/16, IEEE and IEEE Robotics and Automation Soc. (2016), pp. 91-94.

[3] J. Salvia, R. Melamud, S. A. Chandorkar, S. F. Lord, and T.W. Kenny, "Real-Time Temperature Compensation of MEMS Oscillators Using an Integrated Micro-Oven and a PhaseLocked Loop," Microelectromechanical Systems, 19, 1, (2010).

[4] C. Jha, M. A. Hopcroft, S. A. Chandorkar, J. C. Salvia, M. Agarwal, R. N. Candler, R. Melamud, B. Kim, and T. W. Kenny, "Thermal Isolation of Encapsulated MEMS Resonators," Microelectromechanical Systems, 17, 1, (2008).

[5] S. Zaliasl et al., "A 3 ppm $1.5 \times 0.8 \mathrm{~mm} 21.0 \mu \mathrm{A} 32.768 \mathrm{kHz}$ MEMS-Based Oscillator," Solid-State Circuits, 50, 1, (2015).

[6] W. You, B. Pei, K. Sun, L. Zhang, H. Yang, and X. Li, “Oven controlled $\mathrm{N}++\left[\begin{array}{lll}1 & 0 & 0\end{array}\right]$ length-extensional mode silicon resonator with frequency stability of $1 \mathrm{ppm}$ over industrial temperature range". Micromech. and Microeng., 27, 9, (2017).

[7] C. Y. Liu, M. H. Li, H. G. Ranjith and S. S. Li, "A 1 MHz 4 ppm CMOS-MEMS oscillator with built-in self-test and sub$\mathrm{mW}$ ovenization power," Technical Digest of 2016 Int. Electron Devices Meeting, San Francisco, CA, 12/3-7/16, IEEE, (2016), pp. 26.7.1-26.7.4.

[8] Z. Wu and M. Rais-Zadeh, "A Temperature-Stable Piezoelectric MEMS Oscillator Using a CMOS PLL Circuit for Temperature Sensing and Oven Control,"

Microelectromechanical Systems, 24, 6, (2015).

[9] L. Comenencia Ortiz, et. al, "Thermal Effects of Ovenized Clocks on Episeal Encapsulated Inertial Measurement Units", Technical Digest 2018 MEMS, Belfast, Ireland, 6/21-25/18, IEEE and IEEE Robotics and Automation, (2018).

\section{CONTACT}

*L. Comenencia Ortiz, tel: +1-787-608-9044;

lcomenen@stanford.edu 